DEPARTAMENTO DE MICROHIOLOGIA E IMUNOIOGIA

Diretor: l'rof. Dr. Paulo M. (i. de I,acerda Ir

\title{
OBSERVAÇÕES PRELIMINARES SOBBRE A FLORA BACTERIANA DAS METRITES BOVINAS (")
}

\author{
PIIEAMINARY OBSFIRYATIONG ON BONINF MFIRITIS
}

PALLO M. C. DE: LAC.FAd JR.

D. C. DE liREITAS
Issistenle

\author{
LuLZ ZaNi Néto \\ Assistente
}

\section{$1-$ INTRODICSO}

Vo decorrer das alividades do nosso Departamento, livemos oportunidade de analisar maicrial proveniente de alguns casos de metrite bovina. Chamou nossa atcringan a fredquência com que foram encontrados nesses exames, os germes do grupo coliforme.

Decidinos cutão investigar um maior número de casos, obtendo através de colcgas, amostras de matcrial oriundo de casos agudos e crúnicos de metrite. Reunimos, assim, 49 amostras colhidas em localidades diversas, nas quais pudenos confirma: as primeiras observaçórs.

F' intercssante nolar que as referências bibliográficas sûbre o assunto, embora aburadintes sob o ponto de vista clínico e tcrapêutico, säo escassas sob o pontos de vista bacteriológico.

Num peníodo anterior a 1933, encontrámos observações de Qvivian onde são aponlados como agentes cliológicos, o bacilo coli, cocos diversos e o Corywebacherium pyogenes. A partir dêsse ano, com a accitaçāo geral do papel pulogénico do Trichomonas jaelus e de sua responsabilidade na eliologia das metrites, as observaçues se encaminharam cm sua direçäo e Küst em 1934 com. prova em 71 de 124 casos examinados a existência daquele flagelado. JaEGER (19:34) analisou 51 casos de piometra. Lincontron $18 \%$ estéreis, cêrca de $25 \%$ com Corynelacterium pyogenes e uos restantes $T$. foetus e cocos de vários tipos. Ruxgl: (19.1?) referr.se à frequência das piometras na Polónia e isola de seus casos Brizcella abortus, bacilo coli c C. pyogenes.

(•) Apresentado ao 11 C'ongresso P'an Aurricano de Melicina Veterinárin, realizado em saso Paulo, de 3 a 10 cie ahril de 1954. 
$E^{\prime}$ interessante observar o pessimismo com que vários dêsses autores se referem à infecção causada pelo $C$. pyogenes, cujo prognóstico reputam sempre desfavorável.

Em nosso meio pouco conhecemos a respeito. A presença do Trichomonas fotus em São Paulo, foi assinalada recentemente por D'APıce e Mlíl.o e nāo temos dados referentes à sua incidência em nossos rebaulios. No cutanto, na própria opiniāo dos clínicos que nos forneceram as amostras, tais prucessos in. fecciosos são frequentes $e$, por sua própria nature»a, determinam sérios prejuizos à reproduçâo.

Justamente pela escassez de observaçōes é que resolvemos comunicar nossos resultados preliminares. Entretanto, somente a continuidade das pesquisas c o exame de um grande número de casos nos permitirāo emilir futuramente uma opinião segura sôbre o assunto.

$$
\text { II - MATERIAL, E MrtoduOS }
$$

a) Malcrial esludado: - Constou de 19 amostras colhidas em propriedades localizadas ao redor do município paulista, tôdas elas de criação de grado leiteiro.

b) Coleta das amostras: - Esta operaçāo foi realizada por um de nús e por colegas clínicos que tinham oportunidade de examinar casos de metrite. Para isso, forneciamos tubos de ensaio contendo um estilete metálico montado numa das extremidades com mecha de algodão hidrófilo e na outra con algo. dão engordurado que servia para fechar o tubo. O conjunto era esturilizado em calor sêco, a $180^{\circ} \mathrm{C}$ durante duas horas. No momento de uso, o csliletc crat introduzido cuidadosamente através da vagina para ser embehido no corrinento que escoava espontaneamente pclo colo uterino ou se apresentava após matsisa. gens uterinas efeluadas por via retal.

c) Isolamento das amostras: - Chegados os tuhos ao lizhoritúrio, o material era stmeado em três meios de cultura líquidos: caldo glicosado, caldo bile verde brilhante e caldo nitrogeneto de sódio-cristal violeta. Após 24. horas de incubação a $37^{\circ} \mathrm{C}$, eram feitas observações microscópicas e semeaduras cm placas para isolamento dos germes. Como meios sólidos, usamos com inais fre. quência o ağar sangue e o meio "LMB Agar" (B76 Difco). Isolados os diversos germes, procedíamos a provas culturais e bioquímicas que nos permitiscm identificá-los, tomando como base os tipos descritos no Manual de Sistenlática de Brked, Murray \& Hitchens (Bergey's Manual). 


\section{III - RESLLLTADOS}

Dos 19 casos examinados foram isoladas 54 amostras de germes, assim dis. tribuida: :

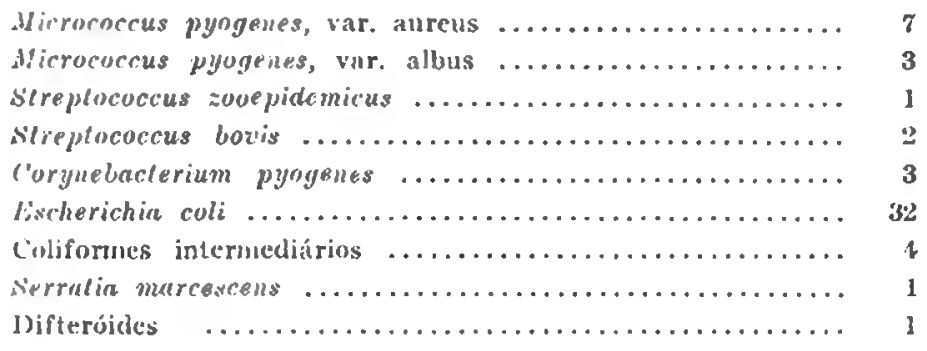

Quatro casos revelaram-se bacteriologicamente estéreis, nos meios por nós empregados.

\section{IV -. DISC:USSiño}

Conforme comentários no início dêste trabalho, a frequência dos germes do grupo coli nas metriles bovinas nos parece ser fato bem evidenciado, pois, em 49 caso. examinados tais germes foram encontrados 36 vêzes. Da sua importância etriógica, como agente primário de processo infeccioso, parece-nos temerário enilir no momento qualquer opinião. Parcce-nos plausivel, entretanto, que a frequência com que são encontrados se ache ligada ao fato de estar a vulva em contacto constante com fezes, permitindo aos germes intestinais instalarem-se facilmente na vagina. Traumatismos, retençôes de placenta, partos distócicos, exsmes de colo uterino com espéculos, manobras de inseminação artificial, seriłn causas suficientes para conduzir êsses germes às proximidades ou a próprio útero. O mesmo mecanismo seria aplicável aos demais germes cncontrados, que, como é sabido, existem largamentc espalhados na natureza. Quanto à inierferência do Trichomonas facus, carecemos de dados sôbre a sua incidência.

Iim que pesem os resultados das pesquisas futuras, julgamos, através destas primciras olsservaçues, que o conhecimento da flora hacteriana das metrites bovinas seja de grande intcrêsse clínico, podendo auxiliar decididamente a orientaçäo terapèutica, mormente se esta última visar a utilizaçảo de antibióticos.

Os autores agradecem aos colcgas dos Departamentos de Zootecnia e de Fisiologia a colaboração prestada na coleta das amostras. 


\section{IRESUMO}

Observações preliminares sóbre a flora bacteriana de metriles bovinas. foram realizadas pelos autores, em material colhido de 19 casos.

Dentre os germes isolados, num total de 54 amostras, 36 pertenciam ao grupu coliforme e os demais assim se distribuiam: estafilococos - 10; estrepto. cocos - 3; Coryncbacterium pyogenes - 3; Serratia marcescens - 1 e bacilos difteróides - 1.

E' focalizada a alta incidência dos germes coliformes. Os autores lembram que os dados que ora apresentam, cmbora preliminares, revestern-se de grande interésse clinico e que, o conhecimento da flora bacteriana das metrites buvinas, poderá ser um grande auxiliar na orientação terapêtuca dêsses processos, principalmente quando estiver em mira a utilização de antibióticos.

\section{SLMMARY}

Prelimirary observations on hovine metrites, regarding their bacteriological flora, have been carried out in a total of 49 cases. Out of 45 microorganisms isolated, 36 were of the coliform group and the others were distributed as follows: staphylococci - 10; streptococci - 3; Corynebacterium pyogenes - 3; Serreria marscecens -1 and diphteroid bacillus -1 .

Attention is called by authors for the significative incidence of the coliform group. They have also realized that experiments on such subject must have a great clinical interest mainly if antibiotical therapeulic is desired.

\section{BIBI.IOGRAFIA}

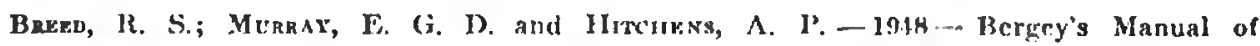
Detcrminative Bacteriolngy: 313. blh ed. Iondon, Batllicre, lindal \& cox.

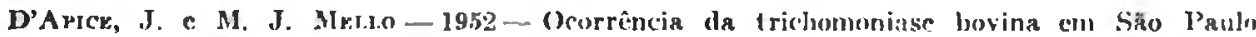
(nota prévia). VII Rouniño Anual de Medicina Veterinária. Säo l'aula, norcon. bro $12 / 16,1952$ (no prilo).

Jazozr - 1934- Inaugural Disscrtation. IIannover. Cit. Dawson, F. I. M. (1950); 13ritish Vet. Jour., 106:111.

Kügt - 1934-1)tsch. ticrarztl. Woch., 12:749; cit. Dawson, F. I. M. (1950); Iritish Vet. Jour., $1106: 111$.

Quintan - 1929 - Dircelor's 15th Annual Report on Veterinary Research for the South African Government at Onderstepourt; cil. Dawson, F. L. M. (1950): British Vel. Jour., $106: 110$.

RuNae - 19.42 - Contribukion on Cow Stcrility. Vet. Record, 51:407-10. 